\title{
Morphological, thermal and annealed microhardness characterization of gelatin based interpenetrating networks of polyacrylonitrile: A hard biopolymer
}

\author{
SANGITA RAJVAIDYA, R BAJPAI* and A K BAJPAI ${ }^{\dagger}$ \\ Department of Postgraduate Studies and Research in Physics, R.D. University, Jabalpur 482 001, India \\ ${ }^{\dagger}$ Department of Chemistry, Government Autonomous Science College, Jabalpur 482 001, India
}

MS received 12 November 2004; revised 13 June 2005

\begin{abstract}
The present paper reports the preparation of full IPNs of gelatin and polyacrylonitrile. Various compositions of gluteraldehyde crosslinked gelatin and $\mathbf{N}, \mathrm{N}^{\prime}$-methylene-bis-acrylamide crosslinked PAN were characterized by SEM and DSC techniques. The IPNs were also thermally pretreated by the annealing process. The effects of annealing temperature on the microhardness of IPNs were studied using the Vickers method. SEM indicates the homogeneous morphological features for IPN. The role of gelatin, AN and crosslinker on the developed hard biopolymer has been described with the help of DSC thermograms and microhardness measurements of annealed specimens and good correlation is observed.
\end{abstract}

Keywords. Interpenetrating network; biopolymer; microhardness; DSC.

\section{Introduction}

An effective role to develop mechanically strong polymeric materials has been through the preparation of interpenetrating polymers which are defined as physical mixture of atleast two polymers which have been synthesized or crosslinked one into the other with no significant degree of covalent bonds between them (Lipatov and Karabanova 1994). The literature richly documents various polymer blends or interpenetrating networks (IPNs) which have been undertaken for study of mechanical properties such as hardness. Although a large variety of polymeric materials have been prepared (Hourston et al 1998; Karabanova et al 2001; Stevens et al 2002), however, IPNs made of natural and synthetic polymers are relatively less reported (Lopas and Felisberti 2003). These materials which combine the mechanical properties of synthetic component with biological properties of the natural one, could result in a novel class of hard biomaterials finding wide spectrum of possible applications in hard tissue replacement (Zhang et al 1993; Hukins et al 1995).

Recently, there has been an increasing interest in the effect of thermal pretreatment on the properties of polymers (Sasuga et al 1989; Cantwell et al 1990). Various physical properties are affected due to the influence of thermal treatment like annealing (Sheldon 1982; Maiti et al 1989). It has been shown that the annealing of such polymers just below their glass transition temperature has

*Author for correspondence (rak_bajpai@rediffmail.com; akbmrl@yahoo.co.in) quite a significant effect on the properties subsequently measured at much lower temperature. In analogy to metallurgical terminology, 'annealing' is used in polymer science to describe the improvement of crystallization by heating to temperature below the melting point, which should lead to the growing of perfect crystalline areas of a crystal and a change to more stable crystal structures.

The gelatin film was synthesized and thermal properties using DSC and thermal mechanical analysis (TMA) were studied (Fraga and Williams 1985). Gelatin was also blended with sugarcane bagasse which showed good mechanical properties when investigated by SEM, thermal gravimetric analysis (TGA), DSC and tensile testing (Chiellini et al 2001). An increase in the engineering yield stress was observed, with a decline in tensile impact strength. With DSC on annealing, a small increase in density along with an endothermic peak at $T_{\mathrm{g}}$ was observed. Various physical properties are affected due to influence of thermal treatment like annealing (Golden et al 1967).

The selection of gelatin as one of the components of IPNs lies in its hydrophilicity, non-toxicity, biodegradability and good living biocompatibility, which makes it a material of first choice in many biomedical applications (Okino et al 2002). The other component of IPN is polyacrylonitrile (PAN) which is a semi crystalline vinylic homopolymer. PAN is widely used for making membrane and offers good resistance (Deepak and Ashwini 2000) and shows good mechanical strength and thermal stability. The microhardness testing is found to be a non-destructive means of characterizing the mechanical performance of polymers (Gonzalez et al 1985). 
Thus, being motivated by the utility of hard polymeric material, the present study aims at developing IPNs of gelatin and polyacrylonitrile and investigating the morphological features with SEM, thermal behaviour using DSC and the effect of thermal pretreatment like annealing on the microhardness of IPNs.

\section{Experimental}

\subsection{Materials}

Gelatin (type A, isoelectric point 7.6) used as a pre-formed biopolymer was obtained from Qualigens, Mumbai and used as received. Acrylonitrile was purchased from Research Lab, Mumbai and freed from the inhibitor by successive washing of the monomer thrice with $10 \% \mathrm{NaOH}$, $10 \% \mathrm{H}_{2} \mathrm{SO}_{4}$ and distilled water and finally distilling the washed monomer under vaccum. Glutaraldehyde and N, $\mathrm{N}^{\prime}-$ methylene-bis-acrylamide were obtained from Loba Chemie, Mumbai and used as crosslinkers for gelatin and polyacrylonitrile, respectively. Potassium persulphate (KPS) and potassium metabisulphite (KMBS) employed as polymerization initiator and activator, respectively were obtained from Loba Chemie, Mumbai and used as received. Triple distilled water was used throughout the investigation.

\subsection{Preparation of IPN}

IPNs were prepared by redox polymerization method as described in our earlier communication (Bajpai and Shrivastava 2002). In a typical experiment, into a $10 \mathrm{ml}$ of gelatin solution $(40 \% \mathrm{w} / \mathrm{v})$, were added $1.64 \mathrm{~g}$ of acrylonitrile (AN), $0.02 \mathrm{~g}$ of MBA, $0.1 \mathrm{~g}$ of glutaraldehyde and $1 \mathrm{ml}$ each of potassium metabisulphite $(0.09 \mathrm{~g})$ and potassium persulphate $(0.01 \mathrm{~g})$. The reaction mixture taken in a rectangular glass pellet $(60 \times 35 \times 5 \mathrm{~mm})$ was kept at room temperature $\left(30^{\circ} \mathrm{C}\right)$ for $48 \mathrm{~h}$. The IPNs so prepared were taken out carefully and allowed to swell for $72 \mathrm{~h}$ so that the unreacted monomer and other chemicals were leached out. The IPN film was dried at room temperature for one week, and cut into equal sized square pieces. The dried IPNs were stored in air-tight polyethylene bags. It is worth mentioning here that in forthcoming sections of the paper, the compositions of IPNs will be expressed as weight fractions $(\mathrm{g} / \mathrm{g})$ of total weight of specimen.

\subsection{Scanning electron microscopy}

The SEMs of pure gelatin and the prepared IPNs were recorded on a scanning electron micrograph (STEREO SCAN, 430, Leica SEM) at IIT, Mumbai.

\subsection{DSC studies}

Differential scanning calorimetric measurements of prepared IPNs were recorded on a DSC instrument (2100,
DuPont) in the temperature range $25-400^{\circ} \mathrm{C}$ under $\mathrm{N}_{2}$ atmosphere and at a heating rate of $10^{\circ} \mathrm{C} / \mathrm{min}$ at IIT, Mumbai.

\subsection{Annealing of IPNs}

The IPNs were heated inside a thermostatically controlled oven. The temperature was increased till the desired temperature was achieved. The IPNs were kept at the definite annealing temperature for a duration of $1 \mathrm{~h}$. The oven was then switched off and allowed to cool by itself up to room temperature. The IPNs were annealed at different temperatures ranging from $50-110^{\circ} \mathrm{C}$ at an interval of $10^{\circ} \mathrm{C}$.

\subsection{Microhardness measurements}

The annealed specimens were indented at room temperature using Vickers diamond pyramidal indenter, mhp 160, attached to Carl Zeiss $\mathrm{NU}_{2}$ microscope. The indenting load chosen was $60 \mathrm{~g}$. For each test, the duration of indentation was kept at $30 \mathrm{~s}$. At least five indentations were made at different points of the specimen and average hardness number was calculated. Usually the values of $H_{\mathrm{v}}$ ranged $\pm 5 \%$ from the average value. The microhardness was calculated by using the relation

$$
H_{\mathrm{v}}=\frac{1 \cdot 854 \times L}{d^{2}} \mathrm{~kg} / \mathrm{mm}^{2},
$$

where $L$ is the load in $\mathrm{kg}$ and $d$ the length of the diagonal of indentation in $\mathrm{mm}$.

\section{Results and discussion}

\subsection{SEM studies}

The SEM micrograph (figure 1(a)) reveals the morphological features for pure gelatin and the appearance of clusters of the aggregated gelatin molecules on the surface results in heterogeneous surface, whereas the SEM micrograph for the IPN as in figure 1(b) indicates more homogeneous surface with hydrophobic moieties scattered on the hydrophilic gelatin matrix.

\subsection{DSC studies}

The thermal studies provide information not only about the thermal properties of the material but also give clues about its structure. In order to gain insights into the structure of IPNs, DSC curves of IPNs of various compositions are constructed and discussed below.

(i) Effect of gelatin: The DSC curves of IPNs containing varying amounts of gelatin in the range 0.349-0.682 $(\mathrm{g} / \mathrm{g})$ are shown in figures $2(\mathrm{a})$, (b) and (c). Generally, an 
endotherm located at a $T_{\mathrm{g}}$ indicates the time-dependent thermal relaxation in the polymer. As shown in the figure, two glass transition temperatures for gelatin are observed in each thermogram. The block copolymer model for the amino acid content of the gelatin explains this occurrence (Fraga and Williams 1985). The first glass transition temperature is a minor one, located around 80$100^{\circ} \mathrm{C}$ and associated with the glass transition of $\alpha$ amino acid blocks in the peptide chain. Detection of this is not easy with a hydrophilic material as water is also lost in the same temperature range. The second more intense glass transition temperature is located around 180$200^{\circ} \mathrm{C}$, and represents the blocks of imino acids, proline, hydroxyproline with glycine. The second $T_{\mathrm{g}}$ is apparently responsible for the overall physical behaviour of gelatin and is one of the most cited and studied (Yannas and Tobolsky 1966).

Another remarkable feature displayed by the thermograms is the influence of increasing gelatin on the second $T_{\mathrm{g}}$. It is clear from the curves that at $0 \cdot 349 \mathrm{~g} / \mathrm{g}$ gelatin, $T_{\mathrm{g}}$ is $166^{\circ} \mathrm{C}$, at $0.518 \mathrm{~g} / \mathrm{g}$ it shifts to $170^{\circ} \mathrm{C}$ while at $0.682 \mathrm{~g} / \mathrm{g}$ of gelatin, $T_{\mathrm{g}}$ appears at $186^{\circ} \mathrm{C}$. Thus, a shift in $T_{\mathrm{g}}$ of gelatin also confirms the increasing degree of crosslinking in the IPN as reported elsewhere (Vazquez et al 1997). Although the thermograms do not show a sharp endotherm at $T_{\mathrm{g}}$ of PAN (which is $105^{\circ} \mathrm{C}$ ), however, melting endotherm of PAN are clearly seen in the range $300-350^{\circ} \mathrm{C}$.

(ii) Effect of acrylonitrile: DSC thermograms of IPNs with $0 \cdot 162 \mathrm{~g} / \mathrm{g}$ and $0.279 \mathrm{~g} / \mathrm{g}$ concentrations of acrylonitrile (AN) are shown in figure 3. The curves clearly point out that with increasing AN content in IPN, the endotherms become quite broad and display a large peak area. This obviously suggests that with increasing AN in IPNs, crystallinity also increases. The thermograms also reveal that at higher AN content a small endotherm appears at $125^{\circ} \mathrm{C}$, which may be assigned to the glass transition temperature of PAN.

(iii) Effect of MBA: In the present study, PAN has been crosslinked with MBA and its influence on the DSC thermograms has been depicted in figures 4(a) and (b) which show two curves for IPNs with $0.0017 \mathrm{~g} / \mathrm{g}$ and $0.0034 \mathrm{~g} / \mathrm{g}$ of MBA. It appears from the thermograms that as the concentration of crosslinker increases, the $T_{\mathrm{g}}$ of IPN slightly increases from $324-332^{\circ} \mathrm{C}$ which is expected also. Another feature displayed by the melting endotherms of PAN is that the peak area substantially decreases from $84-49 \mathrm{~J} / \mathrm{g}$ which indicates a reduction in the crystallinity of IPN.

\subsection{Annealing studies}

The thermal pretreatment of IPNs is found usually to modify their structure, hence, some positive change in their properties can be expected. In annealing, IPNs are subjected to slow cooling, thus providing plenty of time for rearrangement of polymeric chains. The effect of annealing temperature on the $H_{\mathrm{v}}$ of IPNs with varying compositions of gelatin and $\mathrm{AN}$ are discussed below.

(i) Effect of gelatin: Figure 5 illustrates the effect of annealing temperature on the $H_{\mathrm{v}}$ of IPNs for different contents of gelatin in IPNs ranging from $50-110^{\circ} \mathrm{C}$. It can be observed that for $0.682 \mathrm{~g} / \mathrm{g}$ gelatin, the $H_{\mathrm{v}}$ increases in the annealing temperature range from $50-70^{\circ} \mathrm{C}$ and for $0.349 \mathrm{~g} / \mathrm{g}$ and $0.518 \mathrm{~g} / \mathrm{g}$ gelatin specimens the increase is between 60 and $70^{\circ} \mathrm{C}$. Beyond the annealing temperature of $70^{\circ} \mathrm{C}$, the microhardness decreases. It is also seen that as the content of gelatin in IPN increases, the level of $H_{\mathrm{v}}$ increases. It can, therefore, be inferred from the nature of the curves that in the annealing temperature range where the value of $H_{\mathrm{v}}$ increases, the local
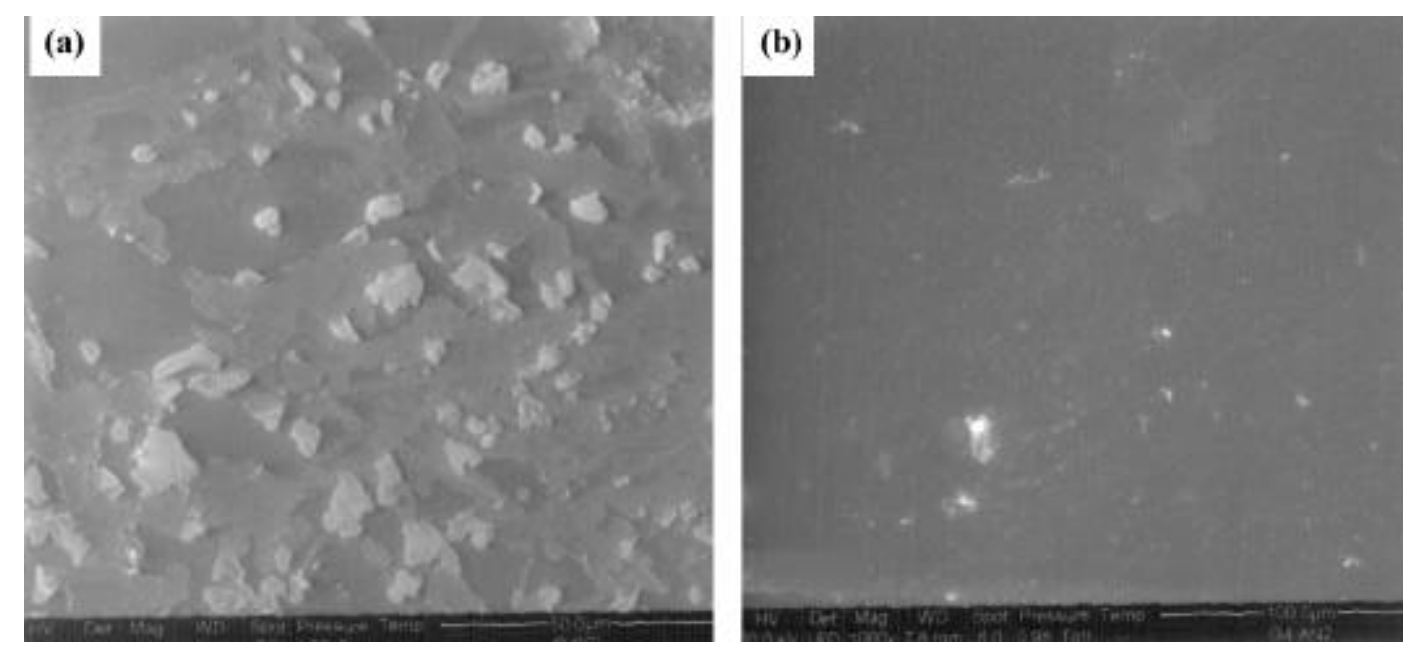

Figure 1. Scanning electron micrograph of (a) gelatin and (b) IPN. 
ordering amongst the polymeric chains of the constituents of IPN occurs which is frozen by slow cooling of the samples. This effect is maximum at $70^{\circ} \mathrm{C}$. Since this annealing temperature range is close to the first glass transition temperature range as detected by DSC studies, hence, the process of annealing provides sufficient mobility of macromolecules and thereafter, the rearrangement process which leads to the hardening of specimens. The increase in the level of $H_{\mathrm{v}}$ with increase in the content of gelatin in IPN can be correlated with the DSC studies, which show the increase of $T_{\mathrm{g}}$ indicating the crosslinking in IPN and increase in crystallinity. The decrease in $H_{\mathrm{v}}$ beyond $70^{\circ} \mathrm{C}$ is due to increased molecular motion which destroys the local ordering. It is further observed that the values of $H_{\mathrm{v}}$ for annealed specimens are less than those of unannealed (at $30^{\circ} \mathrm{C}$ shown in the figure) at all the annealing temperatures except at the temperature of $70^{\circ} \mathrm{C}$ where the $H_{\mathrm{v}}$ values are quite close to that of unannealed specimens. Hence, the overall effect of annealing is to impart softening to the IPNs and the annealing temperature of $70^{\circ} \mathrm{C}$ is optimum to yield moderate hardening.

(ii) Effect of acrylonitrile: Figure 6 shows the variation of $H_{\mathrm{v}}$ with annealing temperature for the IPNs with varying contents of acrylonitrile. It reveals that $H_{\mathrm{v}}$ increases with increase in the annealing temperature range from $50-70^{\circ} \mathrm{C}$. Thereafter, the value of $H_{\mathrm{v}}$ decreases up to $110^{\circ} \mathrm{C}$. The profile is similar for both the IPNs with $0 \cdot 162 \mathrm{~g} / \mathrm{g}$ and $0 \cdot 279 \mathrm{~g} / \mathrm{g}$ contents of acrylonitrile. However, the level of microhardness is higher for higher content of acrylonitrile. Thus, the role of acrylonitrile to develop hard IPN is also established with annealing process. Moreover, the annealing temperature of $70^{\circ} \mathrm{C}$ provides maximum hardening to the IPNs. This temperature is optimum for imparting the molecular ordering.

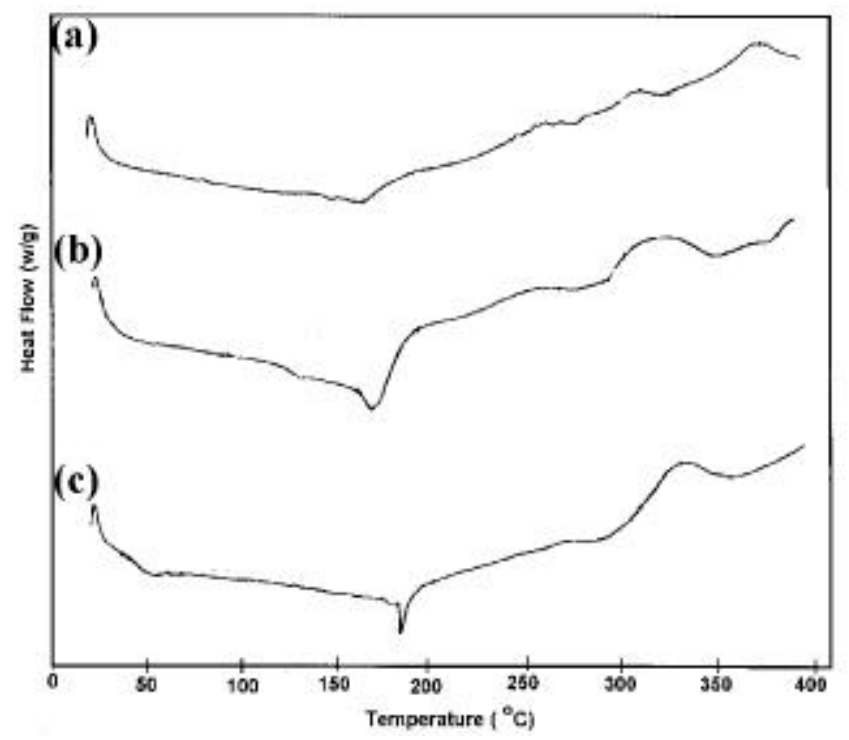

Figure 2. DSC thermograms of IPNs with varying contents of gelatin: (a) $0.349 \mathrm{~g} / \mathrm{g}$, (b) $0.518 \mathrm{~g} / \mathrm{g}$ and (c) $0.682 \mathrm{~g} / \mathrm{g}$.
These features are also confirmed with DSC thermograms which suggests increase in crystallinity in IPNs with increase in AN. When compared with unannealed $\left(30^{\circ} \mathrm{C}\right)$ IPNs, the effect of annealing temperature, in general, is found to soften the IPNs except at the annealing temperature of $70^{\circ} \mathrm{C}$ where the values of $H_{\mathrm{v}}$ for IPN with $0.162 \mathrm{~g} / \mathrm{g}$ content of AN is slightly higher and that with $0 \cdot 279 \mathrm{~g} / \mathrm{g}$ slightly lower to corresponding unannealed IPNs, respectively.

(iii) Effect of MBA: Figure 7 illustrates the variation of $H_{\mathrm{v}}$ with annealing temperature for IPNs with varying contents of MBA (crosslinker). These curves suggest that for IPN with lower content of MBA $(0.0017 \mathrm{~g} / \mathrm{g})$, the

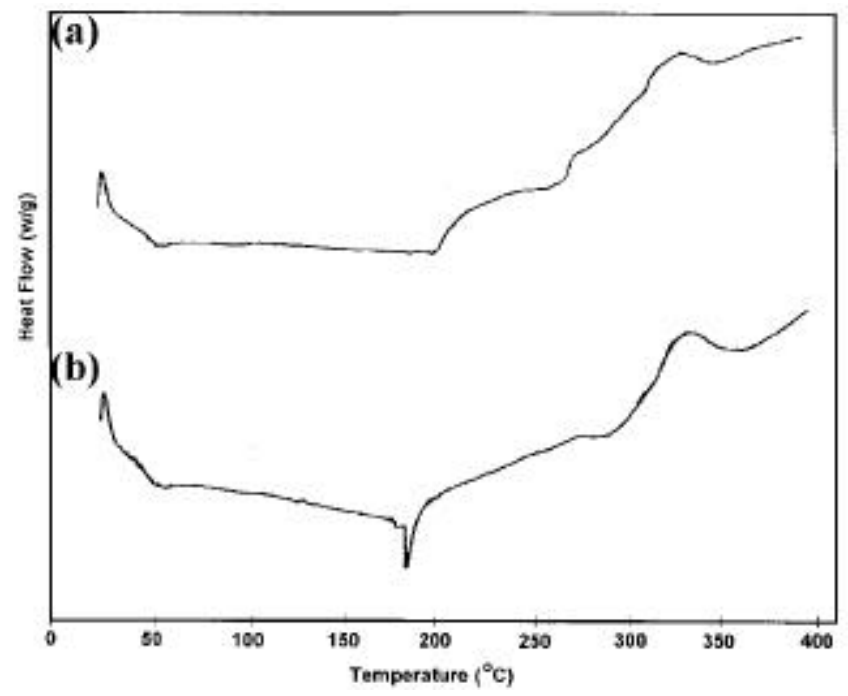

Figure 3. DSC thermograms of IPNs with varying contents of AN: (a) $0.162 \mathrm{~g} / \mathrm{g}$ and (b) $0.279 \mathrm{~g} / \mathrm{g}$.

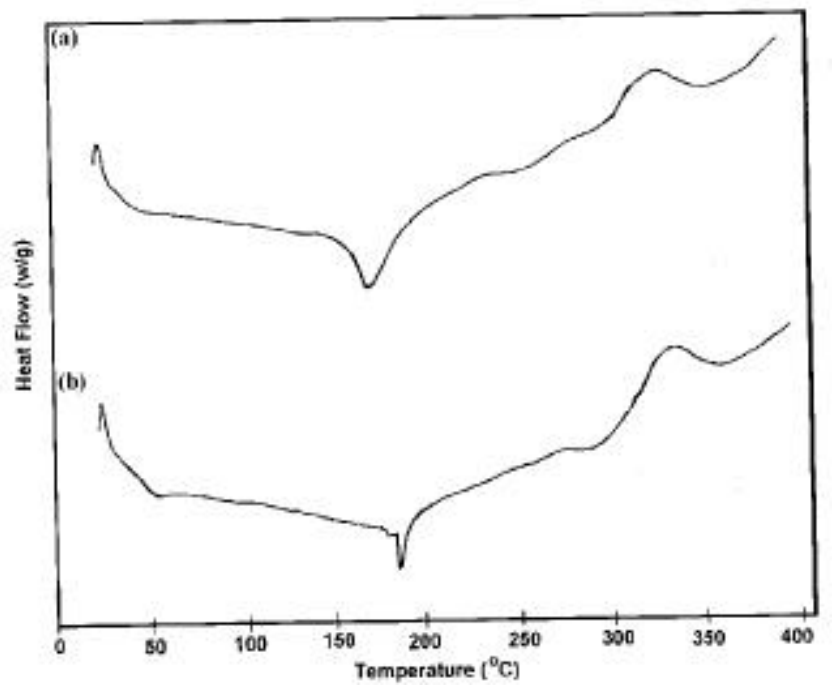

Figure 4. DSC thermograms of IPNs with varying contents of MBA: (a) $0.0017 \mathrm{~g} / \mathrm{g}$ and (b) $0.0034 \mathrm{~g} / \mathrm{g}$. 


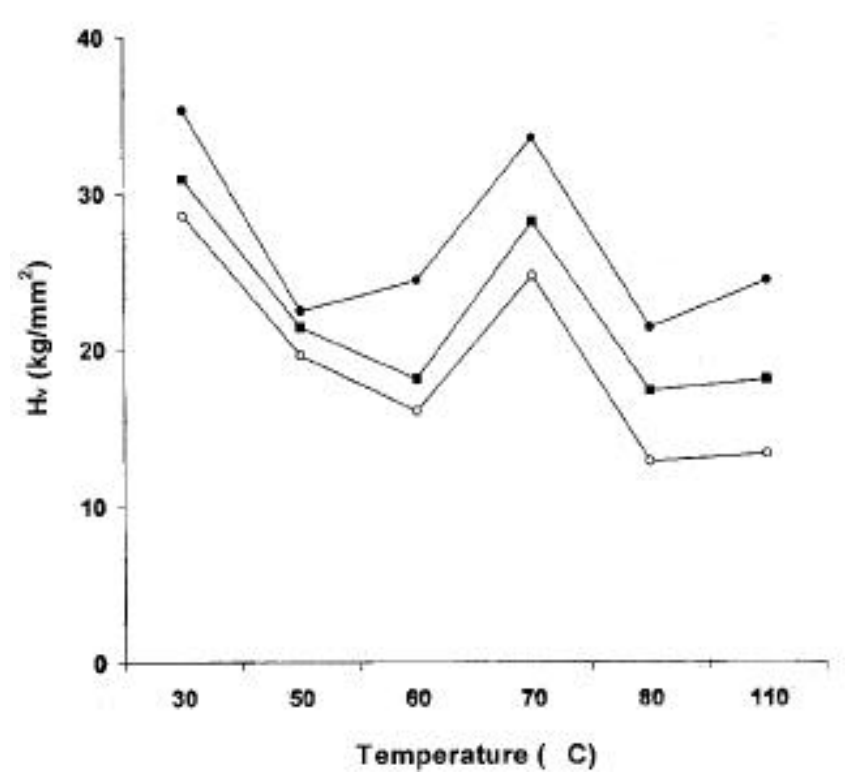

Figure 5. Variation of $H_{\mathrm{v}}$ with annealing temperature with varying contents of gelatin in IPN at the load of $60 \mathrm{~g}$ (o, $0.349 \mathrm{~g} / \mathrm{g} ; \mathbf{\square}, 0.518 \mathrm{~g} / \mathrm{g} ; \bullet, 0.682 \mathrm{~g} / \mathrm{g}$ ).

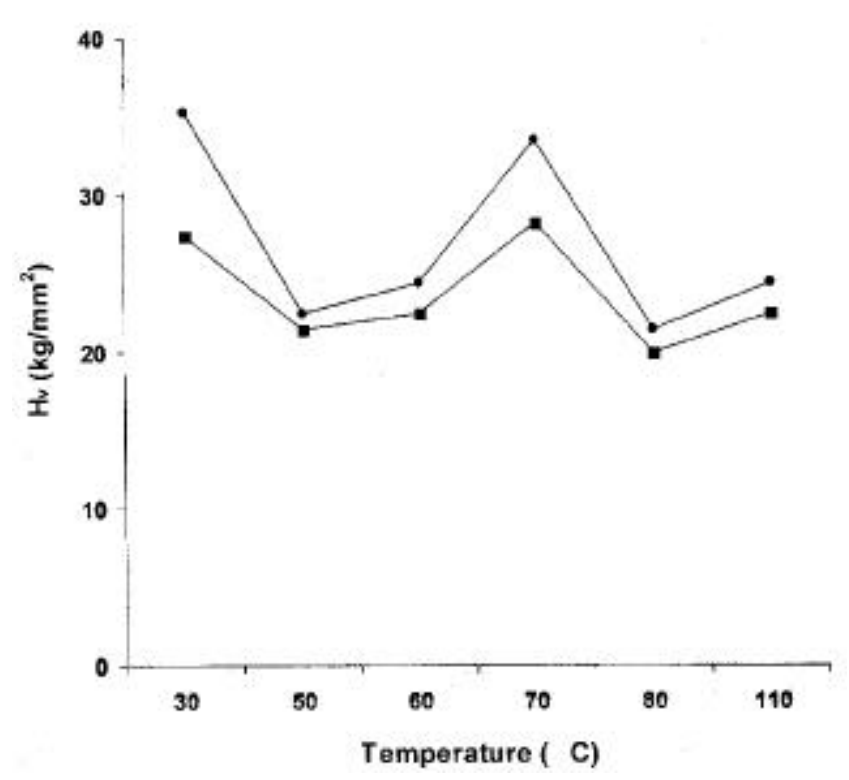

Figure 6. Variation of $H_{\mathrm{v}}$ with annealing temperature with varying contents of AN in IPN at the load of $60 \mathrm{~g}(\bullet, 0.279 \mathrm{~g} / \mathrm{g}$; a, $0 \cdot 162 \mathrm{~g} / \mathrm{g}$ ).

microhardness increases in the annealing temperature range $50-70^{\circ} \mathrm{C}$. Beyond this the $H_{\mathrm{v}}$ values decrease up to $110^{\circ} \mathrm{C}$. The values of $H_{\mathrm{v}}$ in these range of temperatures are also higher than the unannealed $\left(30^{\circ} \mathrm{C}\right)$ specimens, whereas for IPNs annealed with relatively higher content of MBA $(0.0034 \mathrm{~g} / \mathrm{g})$, the level of $H_{\mathrm{v}}$ values are less than those of corresponding unannealed $\left(30^{\circ} \mathrm{C}\right)$ IPN except for $70^{\circ} \mathrm{C}$ where it tends to approach to the value of unannealed specimens. Thus, the role of MBA as crosslinker

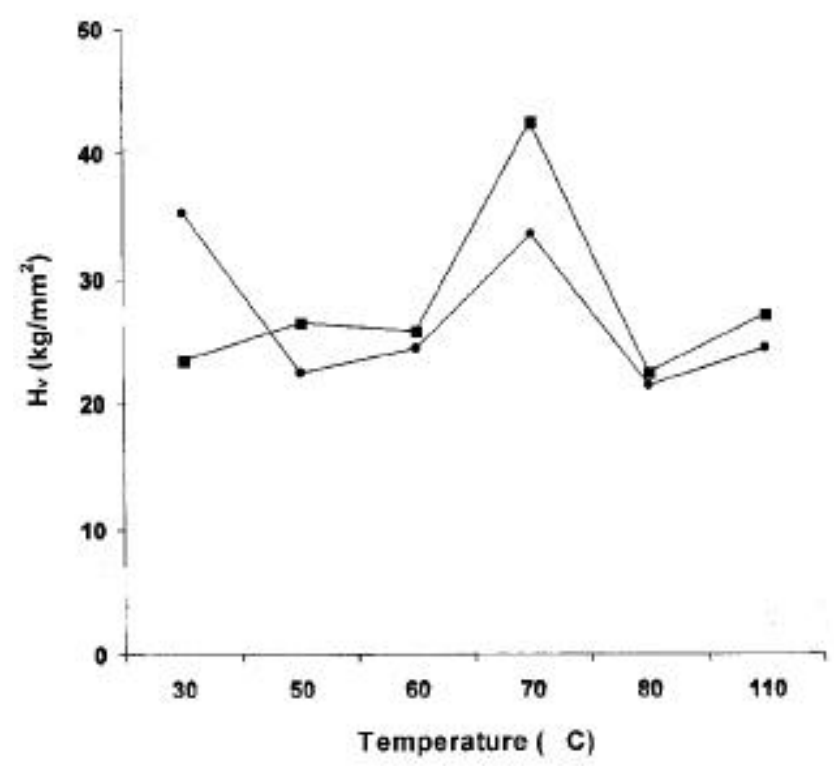

Figure 7. Variation of $H_{\mathrm{v}}$ with annealing temperature with varying contents of MBA in IPN at the load of $60 \mathrm{~g}(\bullet$, $0.0034 \mathrm{~g} / \mathrm{g} ; \mathbf{m}, 0.0017 \mathrm{~g} / \mathrm{g})$.

in the IPN gets enhanced with the annealing process for IPN with relatively lower content of MBA $(0.0017 \mathrm{~g} / \mathrm{g})$, which is the optimum value. The maximum hardening is observed at the annealing temperature of $70^{\circ} \mathrm{C}$. The reduction in crystallinity with increase in the concentration of MBA as detected with DSC thermograms has a correlation with the findings of annealing treatment where the level of microhardness decreases suggesting decrease in local ordering effect due to increased molecular motion.

\section{Conclusions}

The morphological features of pure gelatin reveals heterogeneity and that of IPN indicates homogeneity and hence miscibility of gelatin and PAN in IPN. The thermal behaviour of IPNs on the basis of DSC thermograms shows the existence of two glass transition temperatures. The first one is due to $\alpha$-amino acid blocks in the peptide chain whereas the second one represents the blocks of imino acids, proline, hydroxyproline with glycine, which is responsible for overall physical behaviour. The crosslinking in IPN increases with the content of gelatin and the crystallinity increases with increasing content of AN in IPN. The increase in content of MBA increases crosslinking with reduced degree of crystallinity in IPNs. The process of annealing, in general, softens IPNs. However, the annealing temperature of $70^{\circ} \mathrm{C}$ is optimum, where the degree of crosslinking is comparable to that of unannealed IPNs and in some cases even higher. This temperature is also close to the first $T_{\mathrm{g}}$ of IPNs. A similar correlation is observed between the DSC and annealing results as well as the role of gelatin, PAN and MBA in 
the IPNs. Thus, gelatin based hard IPNs of PAN can be developed with its use as hydrogels.

\section{References}

Bajpai A K and Shrivastava M 2002 J. Biomater. Sci. Polym. Edn. 13237

Cantwell W J, Davis P and Kaush H H 1990 Compos. Struct. UK 14151

Chiellini Emo, Cinelli Patrizia, Elizabeth Grillo Fernandes, ElRefaie S Kenawy and Andrea Lazzeri 2001 Biomacromolecules 2806

Deepak A M and Ashwini K 2000 J. Appl. Polym. Sci. 771782

Fraga Alicia N and Williams Roberto J J 1985 Polymer 26113

Golden J H, Hamnalt B L and Hazella E A 1967 J. Appl. Polym. Sci. 111571

Gonzalez A, Postor J M, Saja J A De and Perej A 1985 Angew. Macromol. Chem. 130201

Hourston D J, Schafer F U, Bates J S and Gradwell M H S 1998 J. Appl. Polym. Sci. 67973

Hukins D W L, Weston S A, Humphries M J and Freemont A J
1995 in Principles of medical biology (eds) E E Bittar and N Bittar (Greenwich CT : Jai Press) 3 p. 181

Karabanova L V, Boiteux G, Gain O, Seytre G, Sergeeva L M and Lutsyk E D 2001 J. Appl. Polym. Sci. 80852

Lipatov Y S and Karabanova L V 1994 in Interpenetrating polymer networks (Lancaster: Technomic) 4

Lopas C M A and Felisberti M I 2003 Biomaterials 241279

Maiti S N, Mishra A and Parekh M J 1989 Indian J. Technol. 27523

Okino H, Nakayama U, Tanaka M and Matsuda T 2002 J. Biomed. Mater. Res. 59233

Sasuga T, Seguchi T, Sakai H, Nakakuru T and Masutani M 1989 J. Mater. Sci. 241510

Sheldon R P 1982 Composite polymeric materials (London and New York: Applied Science Publishers) p. 59

Stevens K R, Einerson N J, Burmania J A and Kao W J 2002 J. Biomater. Sci. Polymer Eds. 131353

Vazquez B, Roman J S, Peniche C and Cohen M E 1997 Macromolecules 308440

Yannas J B and Tobolsky A V 1966 J. Macromol. Chem. 1723

Zhang X, Goosen M F A, Wyss U P and Pichora D $1993 J$. Macromol. Sci. Rev. Macromol. Chem. Phys. C33 81 